\title{
Effect of Rotary Forging on Microstructure and Mechanical Properties of Mg-3Al-1Zn Magnesium Alloy
}

\author{
Shan Jiang*, Chengrong Wu and Taibin Wu \\ Research Institute for New Materials and Technology, Chongqing University of Arts and Sciences, Chongqing 402160, P. R. China
}

$\mathrm{Mg}-3 \mathrm{Al}-1 \mathrm{Zn}$ alloy extruding rods were subjected to rotary forging at temperatures ranging from room temperature to $723 \mathrm{~K}$. The effect of rotary forging on formability, microstructures, and hardness of the samples was investigated. Compared to common forging, rotary forging appeared to significantly promote formability at elevated temperatures, especially at $673 \mathrm{~K}$ and $723 \mathrm{~K}$. Dynamic crystallization occurred in both samples prepared at these two temperatures, whereas newly generated grains in the $673 \mathrm{~K}$ were much finer. A special tilted basal texture was discovered in both samples, exhibiting strong anistropy, and the hardness in the cross section increased from the center to the edge of the samples. [doi:10.2320/matertrans.M2018077]

(Received March 2, 2018; Accepted April 16, 2018; Published June 1, 2018)

Keywords: magnesium alloys, rotary forging, microstructure, mechanical properties, formability

\section{Introduction}

Magnesium alloys exhibit various physical and mechanical properties, such as reduced density, enhanced specific strength, and excellent shock absorption, rendering them an attractive potential alternative for application in the lightweighting of structural components. ${ }^{1-3)}$ It has been reported that the fuel efficiency of passenger vehicles can increase by $6 \% \sim 8 \%$ for each $10 \%$ weight reduction. ${ }^{4-6)}$ Many processes have been carried out to realize the practical application of magnesium alloys, including rolling, ${ }^{7,8)}$ extruding, ${ }^{9,10)}$ and forging. ${ }^{11,12)}$ However, the poor plastic formability originating from their inherent hexagonal closepacked structure greatly increases processing difficulty and limits magnesium alloys' application. Thus, the identification of an adequate method for improving formability and reducing processing costs has become a pertinent focus of magnesium alloy development. Meanwhile, rotary forging $(\mathrm{RF}),{ }^{13,14)}$ otherwise known as orbital forging ${ }^{15}$ or axial rolling, ${ }^{16)}$ has been identified as an effective way to improve formability in some common metals and alloys, such as steel, aluminum, and copper. ${ }^{17-21)}$ Essentially, RF is a type of continuous partial load forming method that can generally decrease the required load pressure or improve the formability of materials. ${ }^{22)}$ Thus, RF may be a suitable method for producing magnesium alloys, although relevant attempts have not been reported. In this paper, RF was applied to magnesium alloys to improve the material's formability.

\section{Experimental Procedure}

Mg-3Al-1Zn (AZ31) magnesium alloy cylinders measuring $30 \mathrm{~mm}$ in diameter and $40 \mathrm{~mm}$ in length were cut from extruded rods. The samples annealed at room temperature, $473 \mathrm{~K}, 573 \mathrm{~K}, 623 \mathrm{~K}, 673 \mathrm{~K}$, and $723 \mathrm{~K}$, respectively, for $30 \mathrm{~min}$ and were forged along the axial direction (AD) by the RF machine, as illustrated in Fig. 1. All samples were prepared at a loading rate of $8 \mathrm{~mm} / \mathrm{s}$. The upper die rotated at a speed of $200 \mathrm{rad} / \mathrm{min}$ around the axis, which

*Corresponding author, E-mail: 382595277@qq.com
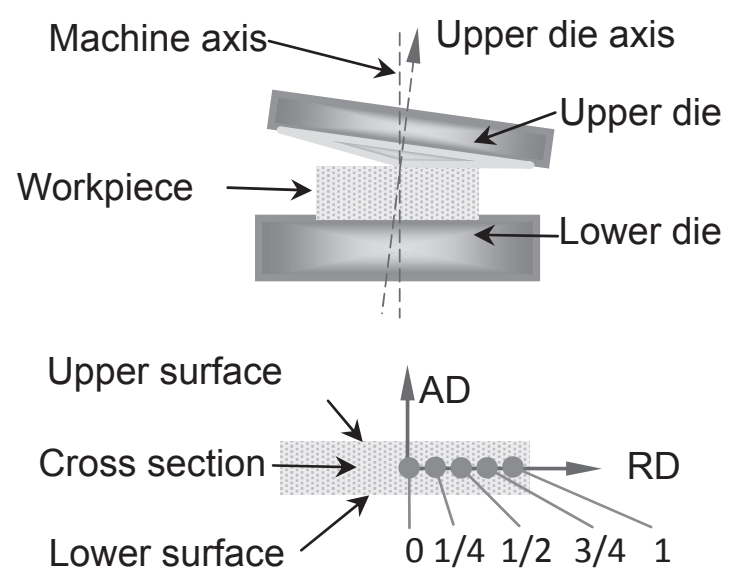

Fig. 1 Schematic diagram of the rotary forging machine.

tilted at a $3^{\circ}$ angle from the machine axis (Fig. 1). For comparison, an equivalent experiment of uniaxial forging (UF) was also conducted. All samples were compressed up to fracture or the maximum load of the press (i.e., 200 tons). The unfractured RF samples were examined using optical microscopy (OM), X-ray diffraction (XRD), electron backscattered diffraction (EBSD), compression testing, and Rockwell hardness testing. For most of these tests, the testing locations were selected at the $1 / 2$ part of the samples' cross section (CS) (Fig. 1), including OM, EBSD, XRD, and compression testing.

The specimens for OM were polished with a series of increasingly fine abrasive papers, etched by a solution of $5 \mathrm{~g}$ nitric acid and $100 \mathrm{~mL}$ ethanol, cleaned with absolute ethanol, and finally dried using an air blower. The energy dispersive spectrometer (EDS) and EBSD measurements were conducted using a Noval 400 NanoSEM scanning electron microscope (SEM) under $20 \mathrm{kV}$, with a working distance of $20 \mathrm{~mm}$ and a tilt angle of $70^{\circ}$. The XRD check was conducted using a Rigaku D/MAX-2500V diffractometer with $\mathrm{Cu} \mathrm{K} \alpha$ radiation $\lambda=1.5406 \AA$ operated at $40 \mathrm{kV}$. The hardness test was conducted with an HRD-150 tester, and the tested locations were selected at points $0,1 / 4$, 
$1 / 2,3 / 4$, and 1 of the samples' CS and upper surface (US), as shown in Fig. 1.

\section{Results and Discussion}

\subsection{Plastic deformation}

As shown in Fig. 2, the total deformation of both processes increased with forming temperatures. However, the increasing magnitude and tendency were different. At RT, the compression ratio (CR) of RF was only $8.8 \%$, slightly smaller than that of UF (11\%). This indicates that the local stress concentration of the RF sample at room temperature accelerated the fracture of the sample. When the temperature rose to $473 \mathrm{~K}$, the $\mathrm{CR}$ of $\mathrm{RF}$ increased to $18.7 \%$, slightly larger than that of UF (14.2\%). With an increase in temperature, RF demonstrated superiority in improving formability. At $573 \mathrm{~K}$ and $623 \mathrm{~K}$, the $\mathrm{CR}$ of the RF sample increased to $41.2 \%$ and $44.0 \%(53.2 \%$ and $58.0 \%$ in true strain), respectively, much larger than that of the UF sample $(16.2 \%$ and $23.8 \%$ or $17.7 \%$ and $27.1 \%$ in true strain, respectively). At $673 \mathrm{~K}$, the $\mathrm{CR}$ of the $\mathrm{RF}$ sample reached $82 \%$ ( $171.5 \%$ in true strain) under maximum pressure of the press without fracturing, whereas the UF sample fractured when the CR reached $52.5 \%$ (74.4\% in true strain). As the
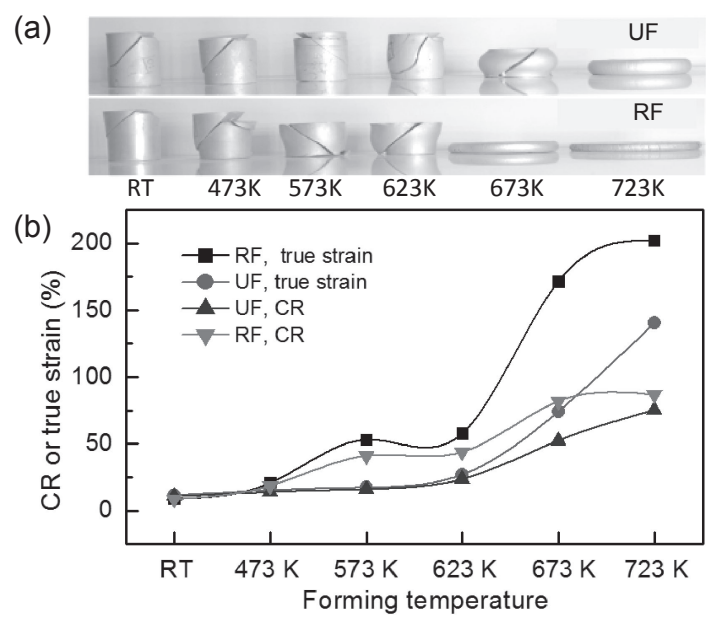

Fig. 2 (a) Appearance comparison of the UF and RF samples. (b) Variation in compression rate and true strain with temperature in the UF and RF samples. temperature climbed to $723 \mathrm{~K}$, the RF and UF samples never fractured; however, the CR of the RF sample reached $86.7 \%$ ( $202.1 \%$ in true strain), still much greater than that of the UF sample, which was $75.5 \%$ (140.6\% in true strain). Therefore, $\mathrm{RF}$ appeared to remarkably enhance the formability at all temperature ranges, especially at high levels of heat.

\subsection{Optical microstructure}

As shown in Fig. 3, the optical microstructure of the $673 \mathrm{~K}$ and $723 \mathrm{~K}$ samples consisted of large, elongated original grains and refined dynamic crystallized (DRX) grains. The elongated grains were approximately hundreds of microns long and tens of microns wide, whereas the refined DRX grains were only several microns on average. As for the $673 \mathrm{~K}$ sample, the elongated grains were surrounded by wide, necklace-shaped DRX grain zones. For the $723 \mathrm{~K}$ sample, the volume fraction of DRX grains greatly increased, such that the elongated grains were distributed like islands. Recrystallization cores are known to be produced in deformed metal in regions with high energy, such as slip bands, twins, boundaries, and grain boundaries, before gradually expanding into equiaxed refined grains and large grains. Therefore, the large volume fraction increase of DRX grains from $673 \mathrm{~K}$ to $723 \mathrm{~K}$ was due to the rising forging temperature. In other words, increasing temperature promoted the growth of DRX grains.

\subsection{EBSD analysis}

To investigate the evolution of the microstructure based on temperature, the inverse pole figure maps of the $673 \mathrm{~K}$ and $723 \mathrm{~K}$ samples were obtained through EBSD as displayed in Fig. 4(a) and 5(a). The colors in the maps indicate the grains' lattice orientations. As shown, the grain boundaries in the DRX zones are easily recognizable. For the $673 \mathrm{~K}$ sample, the average grain size in the fine-grain zone was about $2.5 \mu \mathrm{m}$; for the $723 \mathrm{~K}$ sample, the average grain size in the same zone increased to about $5.6 \mu \mathrm{m}$. The greatly increased grain size from $673 \mathrm{~K}$ to $723 \mathrm{~K}$ can be attributed to the rise in temperature, which speeded up the grain growth rate. Furthermore, the color of the adjacent grains in the $673 \mathrm{~K}$ sample was more uniform than in the $723 \mathrm{~K}$ sample, suggesting that the lattice orientation of grains was preferred. That is, increasing temperature not only increased grain size

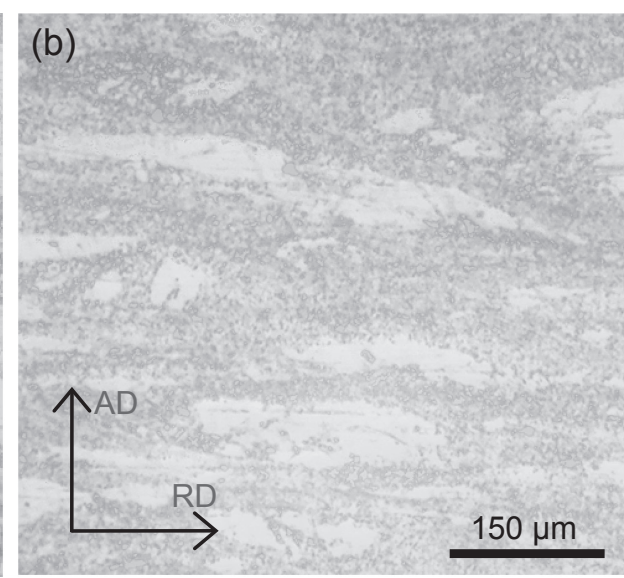

Fig. 3 (a) and (b) are optical micrographs of the RF samples at $673 \mathrm{~K}$ and $723 \mathrm{~K}$, respectively. 

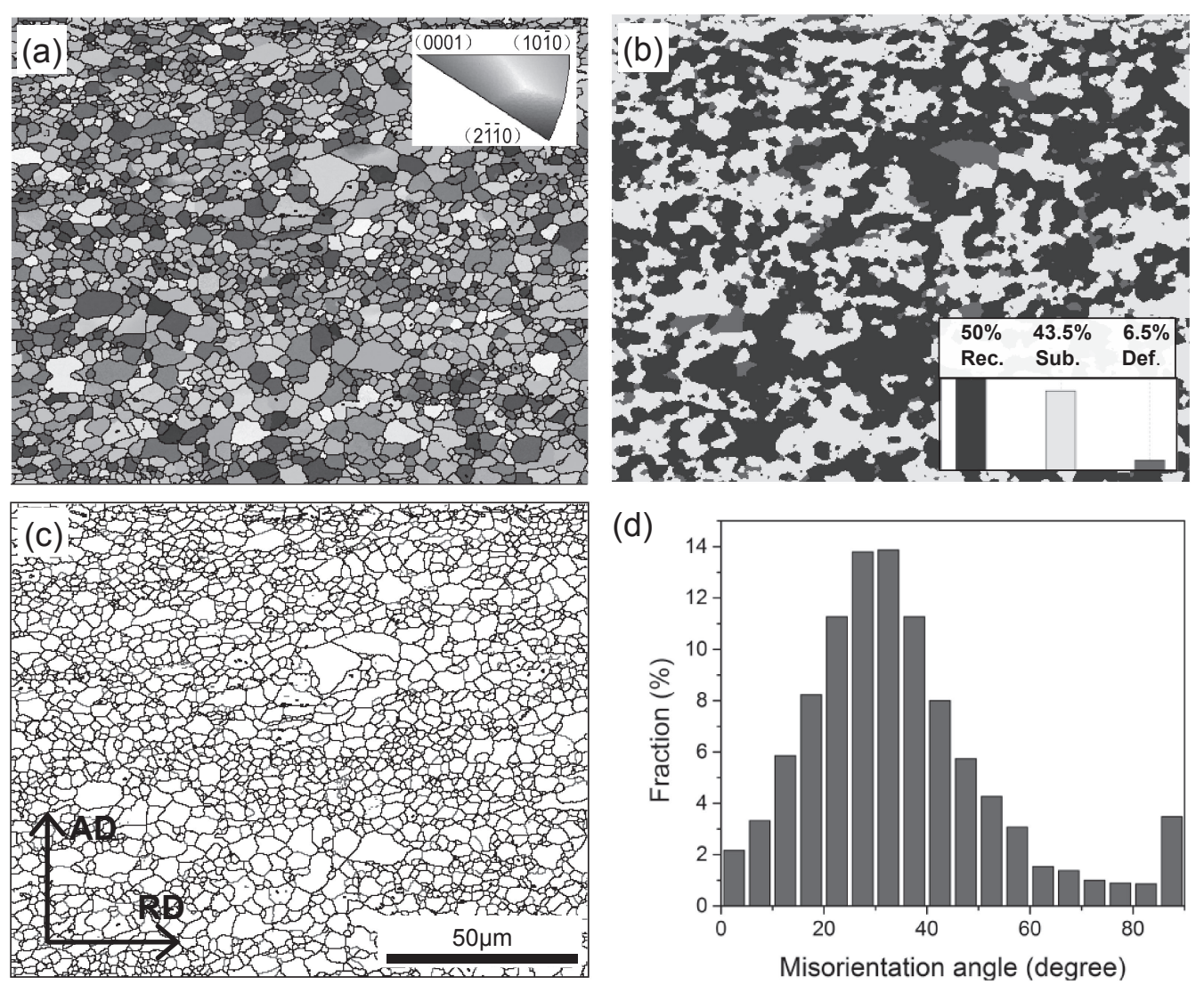

Fig. 4 EBSD measurement results of the $673 \mathrm{~K}$ sample prepared by RF: (a) inverse pole figure map; (b) EBSD map showing the Rec., Sub., and Def. regions; (c) map of low-angle grain boundaries; and (d) graph of the misorientation angle distribution.
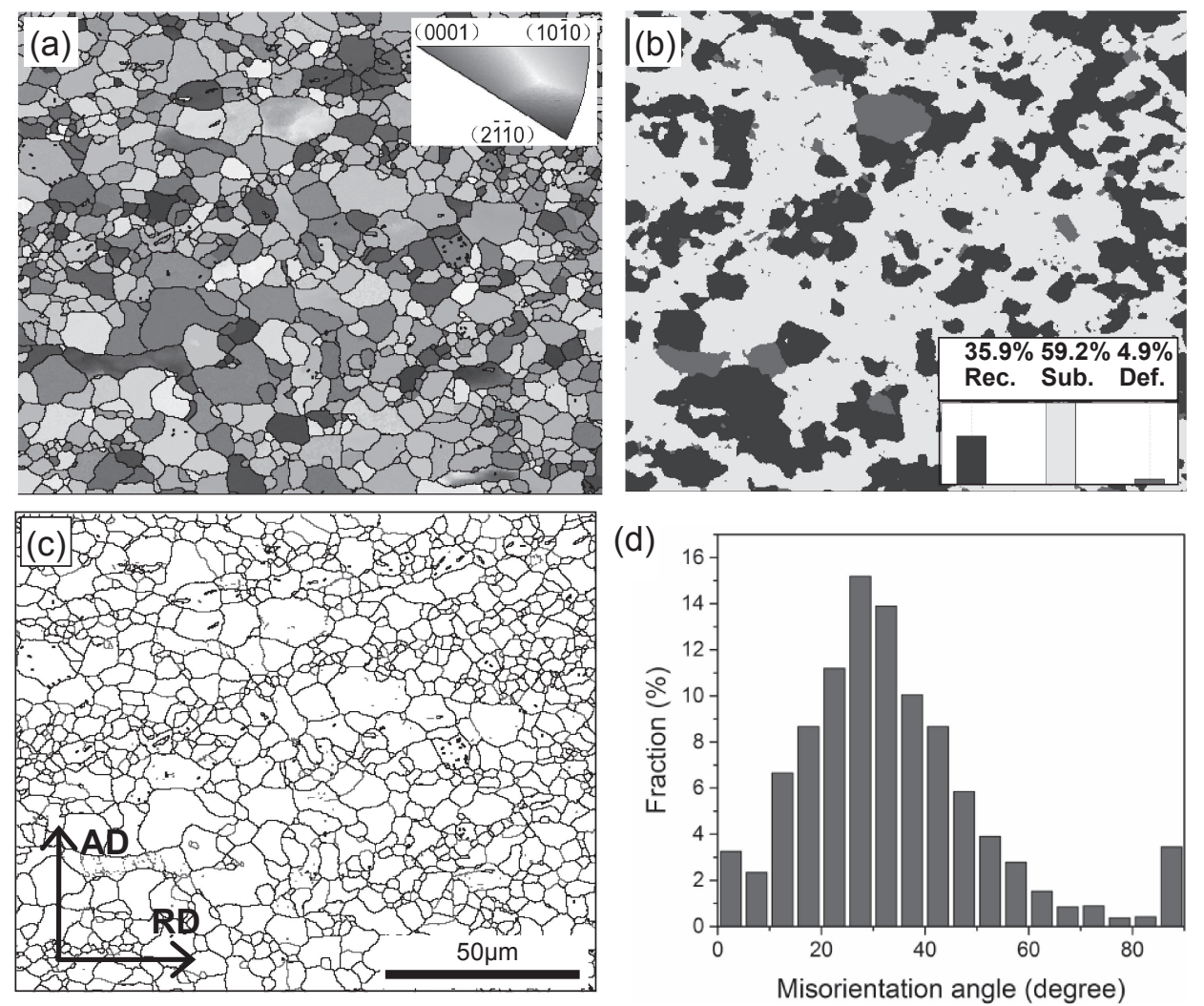

Fig. 5 EBSD measurement of the RF sample prepared at $723 \mathrm{~K}$ : (a) inverse pole figure map; (b) EBSD map showing the Rec., Sub., and Def. regions; (c) map of low-angle grain boundaries; and (d) graph of the misorientation angle distribution. 
(a)
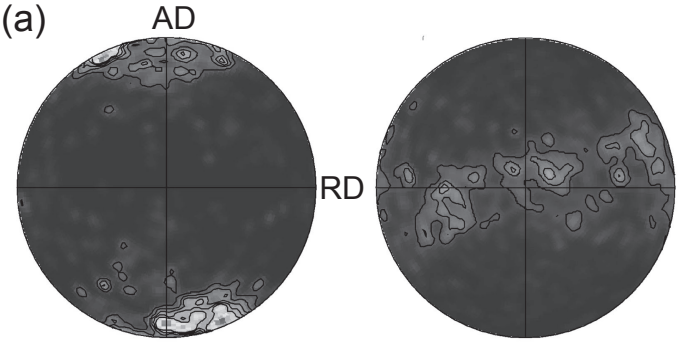

(b)

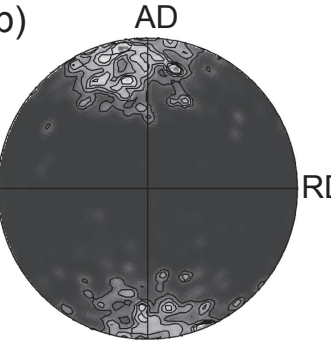

$\{0001\}$

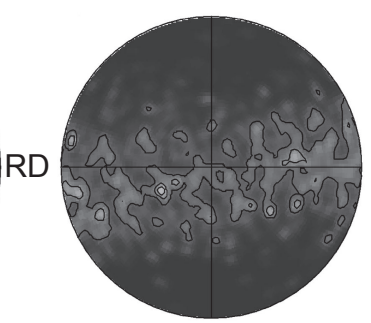

$\{11 \overline{2} 0\}$
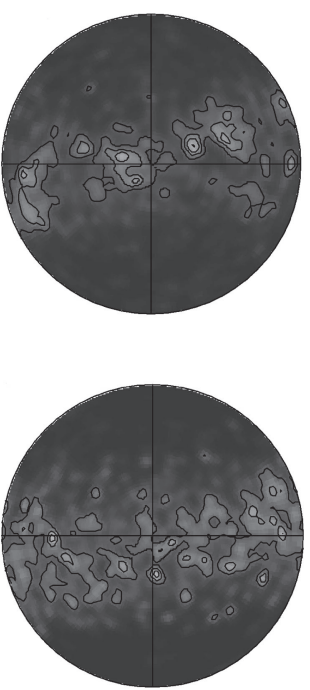

$\{10 \overline{1} 0\}$
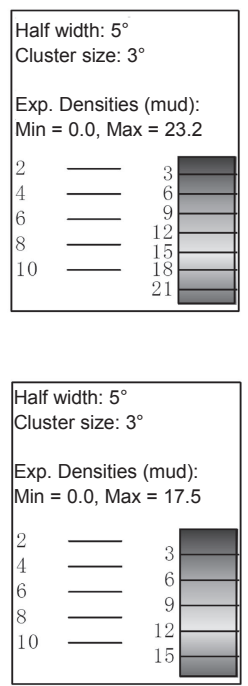

.

Fig. $6\{0001\},\{11 \overline{2} 0\}$, and $\{10 \overline{1} 0\}$ EBSD pole figures of the specimens: (a) sample at $673 \mathrm{~K}$ and (b) sample at $723 \mathrm{~K}$.

but also weakened the grains' orientation distribution. To quantitatively measure texture evolution coinciding with temperature, EBSD pole figures were exported and will be discussed in the subsequent section.

To further investigate the stress distribution of the specimens, the grain type map showing the recrystallized (Rec.), substructured (Sub.), and deformed (Def.) grains was exported, denoted by blue, yellow, and red, respectively, as shown in Fig. 4(b) and 5(b). With respect to the $673 \mathrm{~K}$ sample, the Rec. grains constituted the largest proportion (50\%), followed by the Sub (43.5\%) grains and then the Def. $(6.5 \%)$ grains. For the $723 \mathrm{~K}$ sample, the Sub. grains constituted the largest proportion $(59.2 \%)$, followed by the Rec. grains (35.9\%) and then the Def. (4.9\%) grains. Among these three types of grains, the internal stress of the Def. type was the largest, followed by the Sub. type and finally the Rec. type. Therefore, the difference between the fraction of different type grains should be a significant determining factor related to the mechanical properties.

The maps of low-angle grain boundaries (LAGBs) of $673 \mathrm{~K}$ and $723 \mathrm{~K}$ are shown in Fig. 4(c) and 5(c), respectively. In both maps the LAGBs were distributed uniformly. Most of the LAGBs crossed the grains enclosed by high-angle grain boundaries (HAGBs), and some LAGBs formed independent subgrains. In addition, the fraction of LAGBs in both samples was around 5\%, as shown in Fig. 4(d) and 5(d), which was approximately equal to the fraction of the deformation grains.

Figure 6 displays the EBSD pole figures of the samples at $673 \mathrm{~K}$ and $723 \mathrm{~K}$ corresponding to the measurements in Fig. 4 and 5, respectively. As shown, all samples exhibited a typical basal texture; however, the maximum texture intensity of the $673 \mathrm{~K}$ sample was 23.2 , much larger than that of the $723 \mathrm{~K}$ sample (17.5). In addition, the basal planes of texture were not parallel to the USs of the samples but rather formed a small angle. The result was somewhat different from that observed in uniaxial compression or bidirectional rolling. For the extruded magnesium rods, the basal planes of texture were aligned parallel to the vertical axis, and when they were subjected to uniaxial compression along the axis, the $\{0001\}$ basal planes rotated so a $90^{\circ}$ angle was normal to the axis. The texture features of the samples suggest that the deformation mechanism in RF of magnesium alloys is similar to unidirectional rolling. For an arbitrary blank point in RF, samples were subjected to repeated unidirectional shear stress from the upper dies, resulting in local rolling deformation. The texture feature of RF technology can thus be used to regulate the texture type to meet specific requirements.

\subsection{XRD characterization}

To investigate the samples' macroscopic anistropy, XRD measurements were taken from two normal surfaces: the CS and upper surface (Fig. 1). The patterns of the $673 \mathrm{~K}$ and $723 \mathrm{~K}$ samples are shown in Fig. 7. Both patterns measured in the US had the same three strongest diffraction peaks, sequenced as $\{0001\},\{10 \overline{1} 1\}$, and $\{10 \overline{1} 3\}$; for the CS patterns, the sequence of the three strongest diffraction peaks was different, sequenced as $\{10 \overline{1} 1\},\{10 \overline{1} 0\}$, and $\{11 \overline{2} 0\}$,

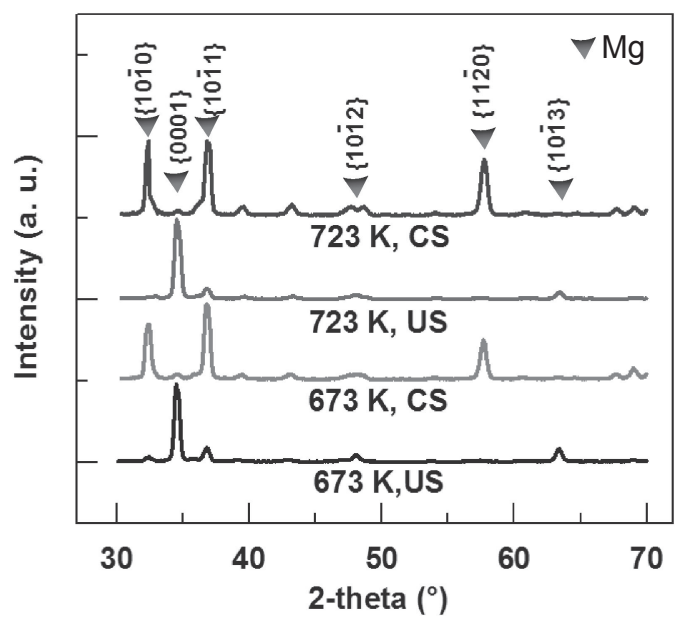

Fig. 7 XRD patterns in the $673 \mathrm{~K}$ and $723 \mathrm{~K}$ samples measured in the US and CS. 


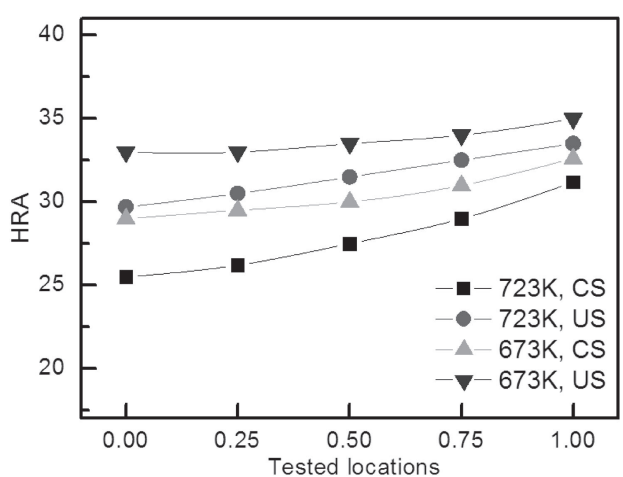

Fig. 8 Rockwell hardness-tested sites curves of the samples of $673 \mathrm{~K}$ and $723 \mathrm{~K}$.

respectively. These results indicate that a strong basal texture formed in both samples where the $\{0001\}$ basal planes were parallel to the US. The development of basal texture can be attributed to two types of grain movement: the rotation of original large grains and the orientated growth of newly generated DRX grains. First, the basal slip was always the preferential slip system in magnesium alloys, and when it was activated, all deformed grains were inclined to rotate their orientations to make the basal planes parallel to the direction of shearing stress. Second, although the newly generated recrystallization cores were oriented randomly, their growth was restricted by the specified sustained stress. As a result, their growth direction was preferred to certain directions favorable for basal texture formation.

\subsection{Hardness test}

Hardness tests were conducted to examine the hardness distribution of the samples. Figure 8 shows the hardness curves of the $673 \mathrm{~K}$ and $723 \mathrm{~K}$ samples tested in the CS and US. As shown, both curves exhibited a tendency to increase from the center to the edge of the samples. Both samples' tested hardness in the US was larger than in the CS. Results were consistent with our predictions. When being formed by RF, the surface of the heated samples would be rapidly cooled by the cold dies, resulting in a remarkable work hardening effect around the colder areas. The regions with the greatest temperature decrease were near the samples' US and lower surface; the temperature drop was the smallest within the center of the samples because of heat conduction. At the same time, the samples' temperature reduction was compensated for by newly generated heat during forging. Obviously, this compensation was more remarkable in regions subjected to larger strains (i.e., the center). When testing hardness in the CS, each hardness value in the $673 \mathrm{~K}$ sample was larger than corresponding sites in the $723 \mathrm{~K}$ sample. This finding suggests that the strain strengthening effect was superior to that of fine-grain strengthening. As evidence, the fraction of the substructured grains at $723 \mathrm{~K}$ $(59.2 \%)$ was larger than at $673 \mathrm{~K}(43.5 \%)$.

\section{Conclusion}

(1) RF technology can greatly promote formability at a wide range of temperatures, especially at elevated temperatures. The true strain of RF samples increased to
$171.5 \%$ at $673 \mathrm{~K}$ and $202.1 \%$ at $723 \mathrm{~K}$, much larger than that of UF samples $(74.4 \%$ at $673 \mathrm{~K}$ and $140.6 \%$ at $723 \mathrm{~K})$.

(2) In the $673 \mathrm{~K}$ and $723 \mathrm{~K}$ samples, a special tilted basal texture formed and a strong anistropy was exhibited. Both samples consisted of elongated original grains and refined DRX grains. For the $673 \mathrm{~K}$ sample, the DRX degree was less complete, whereas the DRX grain size was much finer. Although the fraction of deformed grains in both samples was similar, the fraction of substructured grains at $723 \mathrm{~K}(59.2 \%)$ was larger than at $673 \mathrm{~K}(43.5 \%)$.

(3) In both samples of $673 \mathrm{~K}$ and $723 \mathrm{~K}$, the hardness increased from the center to the edge of the samples. The hardness in the $673 \mathrm{~K}$ sample was larger than corresponding sites in the $723 \mathrm{~K}$ sample.

\section{Acknowledgements}

This work is supported by the National Natural Science Foundation of China (Grant no. 51301215 and 51504052), Chongqing Research Program of Basic Research and Frontier Technology (NO.cstc2017jcyjBX0051), Talent Project of Chongqing University of Arts and Sciences (Grant no. R2014CJ04 and 2017RXC24) and The Scientific and Technological Research Program of Chongqing Municipal Education Commission (Grant no. KJ1601117).

\section{REFERENCES}

1) M. Bamberger and G. Dehm: Annu. Rev. Mater. Res. 38 (2008) 505533.

2) X. Chen, J. Liu, Z. Zhang and F. Pan: Mater. Des. 42 (2012) 327333.

3) J.J. Kim and D.S. Han: Mater. Trans. 49 (2008) 894-897.

4) W.J. Joost: JOM 64 (2012) 1032-1038.

5) N. Tahreen, D.L. Chen, M. Nouri and D.Y. Li: Mater. Sci. Eng. A 594 (2014) 235-245.

6) N. Tahreen, D.F. Zhang, F.S. Pan, X.Q. Jiang, C. Li, D.Y. Li and D.L. Chen: J. Alloys Compd. 615 (2014) 424-432.

7) H. Zhang, G. Huang, L. Wang, H.J. Roven and F. Pan: J. Alloys Compd. 575 (2013) 408-413.

8) W. Tang, S. Huang, D. Li and Y. Peng: J. Mater. Process. Technol. 215 (2015) 320-326.

9) S.M. Masoudpanah and R. Mahmudi: Mater. Des. 31 (2010) 35123517.

10) K. Xia, J. Wang, X. Wu, G. Chen and M. Gurvan: Mater. Sci. Eng. A 410-411 (2005) 324-327.

11) S. Jiang, S. Chen, H. Ni, T. Wu, T. Zhang and M. Wang: Int. J. Mater. Res. 108 (2017) 750-757.

12) Q. Chen, D. Shu, C. Hu, Z. Zhao and B. Yuan: Mater. Sci. Eng. A 541 (2012) 98-104.

13) X. Deng, L. Hua, X. Han and Y. Song: Mater. Des. 32 (2011) 13761389.

14) L.B. Aksenov and S.N. Kunkin: Adv. Mech. Eng. 22 (2015) 1-5.

15) R. Shivpuri: J. Mater. Shap. Tech. 6 (1988) 55-71.

16) L. Guo and H. Yang: Int. J. Mech. Sci. 53 (2011) 286-299.

17) X. Han, L. Dong, L. Hua and W. Zhuang: J. Mater. Eng. Perform. 25 (2016) 1182-1190.

18) G. Wang and G. Zhao: J. Mater. Process. Technol. 95 (1999) 112-115.

19) S. Yuan, X. Wang, G. Liu and D. Chou: J. Mater. Process. Technol. 86 (1999) 252-256.

20) X. Han and L. Hua: Tribol. Int. 44 (2011) 1742-1753.

21) L. Dong, X. Han, L. Hua, J. Lan and W. Zhuang: J. Mech. Sci. Technol. 29 (2015) 1619-1628.

22) X. Han and L. Hua: J. Mech. Sci. Technol. 23 (2009) 2668-2678. 